\title{
ALADI. ALGUNAS HIPÓTESIS SOBRE SU CONFIGURACIÓN $(1980-1995)^{1}$
}

\author{
ALADI. SOME HYPOTHESES ON ITS \\ CONFIGURATION (1980-1995)
}

Por:

Juan Camilo Buitrago ${ }^{2}$

Profesor del Departamento de Diseño

Universidad del Valle

juan.camilo@usp.br

Colombia

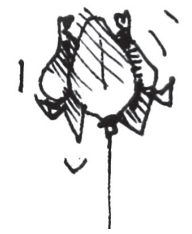

\section{Marcos da Costa Braga ${ }^{3}$}

Profesor en la Facultad de Arquitectura e Urbanismo Universidad de São Paulo

bragamcb@usp.br

Brasil

Resumen: Basado en el enfoque que ofrece la historia social e inserto en el marco teórico de la sociología de las profesiones, este texto tiene la intención operativa de organizar algunas hipótesis sobre la constitución de ALADI. Se comprende como un análisis que apenas corresponde a la revisión de varios documentos escritos dejados por el proceso - actas, acuerdos escritos, artículos de opinión, etc.-. De hecho está concebido como el primer paso de una tesis en proceso hacia el entendimiento de la relación entre las motivaciones que permitieron la creación y el funcionamiento de la Asociación entre 1978 y 1995, como evidencia de la construcción de una mirada crítica de un grupo de latinoamericanos sobre el proceso de desarrollo que implementaba la región.

Palabras clave: Diseño en Latinoamérica, historia del diseño, sociología del diseño.

Abstract: Based on the approach that offers social history and inserted in the theoretical framework of the sociology of professions, this text is intended operational organize some assumptions about the constitution of ALADI. It includes an analysis that corresponds only to the review of several written documents left by the process -acts, written agreements, opinion articles, etc. -. In fact, conceived as the first step toward understanding the relationship between the motivations that led to the creation and operation of the Association between 1978 and 1995, as evidence of the construction of a critical eye on a group of Latinamerican the development process that implemented the region.

Keywords: Latinamerican design, history of design, sociology of design. 
Resumo: Com base na abordagem que oferece a história social e inserido no quadro teórico da sociologia das profissões, este texto destina-se operacionalmente a organizar algumas hipóteses sobre a constituição da ALADI. Ele compreende uma análise que corresponde apenas à revisão de vários documentos escritos deixados pelo processo atos, artigos escritos, de opinião, etc -. Foi concebido como o primeiro passo de uma tese em andamento para compreender a relação entre as motivações que levaram à criação, e o funcionamento da Associação, entre 1978 e 1995, como evidência da construção de um olhar crítico de um grupo de latinoamericanos sobre o processo de desenvolvimento que a região implementava.

Palavras-chiave: Design na Latinoamerica, história do design, sociologia do design.

\section{Los primeros pasos}

En 1978, un grupo de latinoamericanos consintió en México la idea de crear ALADI: Asociación Latinoamericana de Diseño Industrial. Con un discurso de reivindicación cultural, apoyado en la relación diseño-tecnología-dependencia, parece que los fundadores de la asociación pretendieron ponerse en contra de quienes querían negarle a Latinoamérica la posibilidad de configurar su propia realidad (Pamio, 1981) así como configurar una estructura para el control ocupacional de una disciplina joven en la región. Con una mirada muy precisa sobre la promoción de los ideales del Diseño Industrial como vehículo para la conquista del desarrollo económico, social y cultural en la región y la resolución de las necesidades fundamentales de "nuestros pueblos", ALADI es creada en Bogotá en 1980 y funciona hasta 1995 bajo un esquema de dirección por períodos sucesivos entre sus distintos. Los principales países involucrados en el proceso y, por lo determinado hasta ahora, los más activos promotores de ALADI fueron Colombia, Brasil, México, Cuba y Argentina: los cuatro primeros, incluso, como sedes directivas y Argentina igualmente activa en todas las reuniones que le dieron forma a la Asociación ${ }^{4}$.

Por razones que deben establecerse, el funcionamiento de ALADI, en ese primer modelo, se difumina desde 1995, dejando como huella de la historia del Diseño Industrial latinoamericano, la impronta del funcionamiento de un cuerpo asociado que reunió durante 15 años (de crisis económica y moral en la región) el trabajo de 11 o más países en torno de los problemas del desarrollo desde la mirada del Diseño Industrial. Hoy en día, para hacer apología de Marc Bloch, esta impronta es un referente importante que determina, sin saberlo, nuestras acciones del presente (Bloch, 2002).

Según algunos documentos escritos que han dejado las huellas del proceso, ALADI nace como idea en México en 1978, específicamente en Valle de Bravo, en uno de los talleres Interdesign que organizaba ICSID (International Council Societies of Industrial Design). Por razones que es necesario exponer en un escrito posterior, varios latinoamericanos, que en su mayoría resultaban ser los pioneros en la fundación y práctica profesional del Diseño Industrial en sus respectivos países, encontraron en el ejercicio y discursos del ICSID en ese taller prácticas de intervención en la economía y la política de los países de la región ${ }^{5}$. 
Inaceptable para los hijos de la creciente clase media que se habían socializado en los caldeados escenarios universitarios de los años sesenta y setenta en sus respectivos países, embriagados, además y entre muchas otras cosas, con la utopía que significaba el triunfo de la Revolución Cubana en 1958. Sumado a ello, como si fuera poco, casi todos ellos hijos de la ideología modernista de la arquitectura que los encantaba, al punto que varios de ellos acuñaron desde sus preceptos renovadores "la creatividad social"'.

Un grupo de latinoamericanos gesta de manera espontánea y como sugerida reacción a la visión de los directivos del ICSID, la idea de una asociación de diseñadores que representara los intereses de la región, pudiendo tener control sobre ciertas políticas que no parecían estar muy acordes con los intereses de la asociación norteamericana. En palabras de Oscar Pamio: "[...]ALADI nace en un momento histórico crucial, buscando afianzar, a través de la unión, la afirmación de un Diseño Industrial propio, en contra de quienes quieren negarle a

Latinoamérica la capacidad de estructurar su propia realidad[...]" (Pamio, 1981, pág. 1). Es así como se plantea su constitución como Asociación Latinoamericana de Diseño Industrial, haciéndose luego extensiva a las demás especialidades de la profesión (principalmente Diseño Gráfico y de Interiores) que luego de un proceso de dos años, es formalizada en Santandercito, Colombia, en el marco de su primer congreso realizado en Bogotá, en noviembre de $1980^{7}$.

Entre Interdesign-México 1978 (noviembre) y la creación formal de ALADI se dio el acuerdo en la reunión sobre Diseño para el Desarrollo en Bombay, India, en enero de 1979 para proponer su creación y principios generales, "[...] con el fin de fortalecer la cooperación técnica entre los países en desarrollo [... ]” (Uribe, Basilio et al. 198, p. 18). Allí se reunieron Basilio Uribe de Argentina, José Abramovitz de Brasil y Rómulo Polo de Colombia con la presencia de Gui Bonsiepe. A este acuerdo siguió la suscripción formal de la propuesta por los latinoamericanos en el XI Congreso del ICSID, que tuvo lugar en ciudad de México en octubre de 1979 y que fue firmada por 98 asistentes y finalmente, se realizó una reunión informativa en el Primer Simposio Internacional de Diseño de Interiores en Medellín, Colombia, en junio de 1980. A esta última reunión asistieron, entre otros, Gui Bonsiepe y Ricardo Blanco (Argentina), Oscar Pamio (Costa Rica), Oscar Salinas, Claudio Rodríguez, Sergio Rivera y Alejandro Lazo (México) y Jaime Gutiérrez, Jesús Gámez, Hernán Lozano, Mauricio Olarte, Guillermo Sicard, Rodrigo Fernández, Jairo Acero, Fernando Prieto, Luis Zapata y Rómulo Polo por Colombia. 
Al final, la suscripción de ALADI marcó 15 años de relaciones internaciones sobre el diseño entre México, Cuba, Costa Rica, Puerto Rico, Guatemala, Nicaragua, Colombia, Ecuador, Brasil, Chile y Argentina. La Asociación realizó seis asambleas y hasta 1993, seis congresos en Bogotá, La Habana, Río de Janeiro, México D.F y Santa Marta. Según su propia concepción, ALADI fue definida como:

[...] la entidad que agrupa y representa a los diseñadores latinoamericanos que promueven la institucionalización del Diseño Industrial como una disciplina tecnológica necesaria para el desarrollo social, económico y cultural de la región. Basada en el reconocimiento de una problemática común a nuestros países, ALADI promueve a nivel latinoamericano la aplicación del Diseño como disciplina indispensable en el proceso de producción industrial, en materia de objetos y sistemas de información visual, orientado a las necesidades prioritarias de nuestros pueblos [...]. (Aladi, 1980, p. 2)

\section{América Latina y su propia realidad}

El discurso fundador de ALADI, reiterativo en la relación diseño-tecnologíadependencia, deja entrever una postura crítica de sus fundadores con respecto al proyecto que se venía implementando en la región durante el siglo XX (principalmente, desde la década de los años 30). Programas de cooperación internacional, desde los cuales se establecían vínculos entre países desarrollados y países de la región, como sucede con Estados Unidos y algunos otros en Europa, procesos de migración (principalmente en el cono sur), entre otros, supusieron posibilidades para la complejización en las maneras más generales de ver la vida social con los retos de la vida urbana, promovieron el emprendimiento e incluso hicieron soñar a nuestras clases emergentes, con modelos culturales foráneos ${ }^{8}$. Pero de la misma manera dibujaron en varios intelectuales y profesionales, una reserva -por decir lo menos- con las agendas modernizantes de la llamada metrópoli, independientemente de la manera como se encarnaba en cada país?

Una de las seguras críticas latentes en los fundadores tenía que ver con las apuestas económicas de la región, que, como sabemos, se jugaban su primacía desde los tempranos años cuarenta con las propuestas de la CEPAL y aquellas que intentaron resolver sus fisuras en décadas posteriores: principalmente en los años sesenta. Así, de un modelo de protección basado en la industrialización por sustitución de importaciones (ISI), se pasó a uno de promoción de exportaciones mientras el aparato económico parecía aplicarse en un escenario embrionario que no comprendía claramente el sentido de uno u otro ajuste.

El primer modelo -ISI- suponía el establecimiento y fortalecimiento de una industria nacional basado en el principio de la copia y el pago de regalías. El segundo, dependiendo del país, exigía la explotación comercial de productos regionales exóticos y/o de productos nacionales producidos industrialmente bajo un cierto 
lenguaje universal que -en cualquiera de los casos- fueran apetecidos en los mercados internacionales. En esto último, el papel de Estados Unidos resultó determinante para varios países de América Latina, Asia y Europa Oriental unos años después de terminada la Segunda Guerra Mundial ${ }^{10}$. Por medio de visitas constantes de técnicos en la materia a ciertos países, muchas veces agenciados directamente por ICA (International Cooperation Administration) - posteriormente llamado USAid (United States Agency for International Development)- y su alianza con ICSID, se pretendieron por lo menos tres objetivos concretos en materia de desarrollo de nuevos productos para el mercado internacional: rastrear manufacturas exóticas en cada país; entrenar a sus productores con la racionalización de la producción y el mercadeo internacional; y sensibilizar instituciones académicas - universitarias en su mayoría- con los asuntos del diseño industrial ${ }^{11}$.

Uno y otro modelo igualmente pretendían abastecer a una creciente clase media que estaba urbanizando nuestros países y que era necesaria para el proceso de modernización de la región, según el modelo que siguieron. Consciente o inconscientemente en esto se reprodujeron formas y estructuras del llamado american way of life, reflejado en el modus vivendi y la cultura material que era necesaria consumir para que la modernización fuera un proyecto posible. El consumo de objetos nacientes de las nuevas maneras de vivir, como los electrodomésticos, posibles en Brasil por empresas como Walita y Consul (Braga, 2009) o en Argentina bajo el trabajo de SIAM (Devalle, 2009) o Challenger e Imusa en Colombia; la imaginería reproducida en el diseño de carteles para espectáculos -teatro, cine, etc- y en los modelos de peinados, maquillajes, moda y en general roles, parecen transitar - con las variaciones respectivas- y homogenizar gustos en todo el continente en tablados distantes de su epicentro ${ }^{12}$. Todo ello con el telón perfecto, un escenario acorde con el proceso: la 'arquitectura de muros blancos' de la que habló Adolf Loos, que había superado la historia misma y cuyas manifestaciones estaban llamadas a recorrer los rincones de América Latina bajo el estandarte del Estilo Internacional ${ }^{13}$ en: electrodomésticos, espectáculos para el entretenimiento, moda, arquitectura y urbanismo, un latente principio de cambio social y un evidente coletazo homogenizante de nuestras sociedades.

Si se miraba el modelo de promoción de exportaciones, se puede percibir una cierta crítica de los fundadores de ALADI hacia un cierto de tipo de banalización de la creatividad y hacia el énfasis, apoyo y fortalecimiento de unos sectores que los gobiernos privilegiaban por encima de las necesidades latentes de la población. Las denuncias son notorias en diferentes formatos.

Tradiciones productivas milenarias son conservadas con cuidado para mejorarlas y mantener viva la vinculación a la Máquina Nacional, recibiendo así una participación mínima de reconocimiento a la propia asistencia. Recibiendo de las instituciones de gobierno un tratamiento eminentemente romántico (en el cual se refieren constantemente a la conservación del patrimonio tradicional) el productor se ve agobiado por las fuerzas normales del desarrollo: la tecnología automática, la 
aglomeración fabril [...] Familias enteras que subsisten del limpio trabajo artesanal en los Campos de Centroamérica y en las Montañas Andinas, no desearán jamás el caos y la destrucción física que se está determinando con torpeza, a través de las organizaciones de producción snob. (Acero, 1980, p. 12)

En el fondo una explícita e inexplicable dependencia con la llamada metrópoli, desde la cual no se conquistará nunca un proyecto equitativo. Políticamente inaceptable para quien sueña con la autonomía de América Latina; disciplinariamente incorrecto para quien vincula capacidad creativa con resolución de las deficiencias de los demás. En palabras de Rómulo Polo, cofundador de ALADI y primer presidente

[dentro de los problemas que se perciben comunes en Latinoamérica] finalmente, los problemas de la adaptación de innovaciones [convertido] en uno de los verdaderos problemas del subdesarrollo como superación de la dependencia científica y tecnológica, y por lo tanto la cultural y la económica. (Polo, 1980, p.17)

Un problema que era necesario superar.

\section{Creatividad social y crisis de la arquitectura moderna}

Es posible atreverse a señalar algunas generalidades en la postura de sospecha que alimentó la mirada crítica de los fundadores de ALADI con respecto al proyecto modernizante en la región, y que, como principios conceptuales, dieron origen a la asociación ${ }^{14}$.

Uno de ellos, viene desprendido de la ruptura experimentada por la arquitectura misma a finales del siglo XIX con las llamadas Bellas Artes, que resultó desembocando en la reformulación -algunos dirían: la emancipación- de su jurisdicción y los enfoques que son de su discrecionalidad como campo, durante las primeras décadas del siglo $\mathrm{XX}^{15}$.

Como es conocido, desde las perspectivas de Sullivan y Wrigth en Estados Unidos, hasta las apuestas de Loos, Muthesius, Gropius, Le Corbusier, Mies van der Rohe y otros en Europa, el principio de una arquitectura

funcional opacó el ejercicio de reproducción de estilos; varios de ellos, como Adolf Loos, concibiendo y construyendo al ornamento como un enemigo de enormes proporciones contra el cual era necesario construir barricadas para contenerlo. 
Tales perpectivas resultan historicamente comprensibles así como los postulados que engendró ciertos años después. En función de oponerse a tal enemigo, e intentando ser coherentes con el llamado histórico que sentían al frente, los arquitectos modernos tomaron distancia con lo que comprendieron como una manifestación egoísta de la creatividad. Para varios de ellos, el ejercicio de crear debía estar íntimamente ligado con el uso de las posibilidades productivas de la máquina, que representaba la racionalización del material y los procesos y garantizaban la reproductibilidad: sublime evidencia de la edad de la razón y de la conquista de las utopias más románticas del hombre ilustrado $^{16}$. De tal manera la creatividad no podría ser usada en función última de la satisfacción de sus apetitos y padecimientos estéticos como creadores -como según ellos sucedía con arquitectos y artístas decimonónicos-, sino que debía estar alineada con el firme propósito de resolver las necesidades de quienes habitarían alguna de sus obras: con ello podría conquistarse el ideal de la prosperidad ilimitada para todos, con la cual Giddens (1997) caracteriza la modernidad.

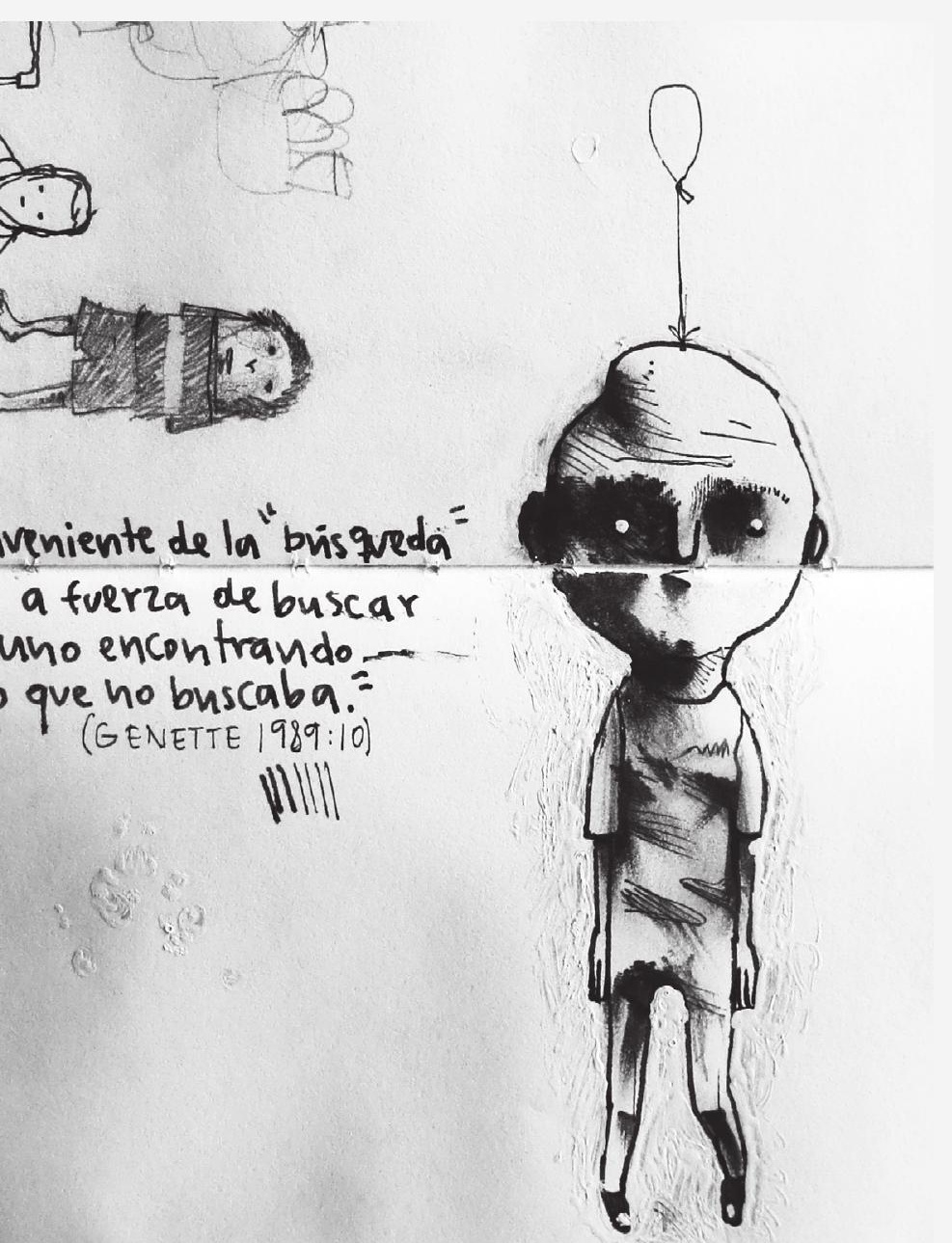

El proceso que cada país latinoamericano vivía con respecto a sus respectivas apuestas por la modernización, en conjunto con diferentes coyunturas, como las mutuas migraciones entre Europa y América Latina y/o de varios países de la región y Estados Unidos, suponen el tránsito y la influencia de estas ideas en los fundamentos y las reformas de la arquitectura en la región desde los años cuarenta ${ }^{17}$. De tal manera es notoria la distancia que toma la disciplina con respecto a las Bellas Artes y su traducción arquitectónica -neoclasicismo- en varios países de América Latina, al tiempo que se vincula conceptual y técnicamente con algunas otras áreas como la ingeniería. En esto se deja ver que la traducción de los principios de la modernidad sugiere un rompimiento de la arquitectura con las artes y tiende lazos con aquellos campos que parecían llamados a consolidarla - a la modernidad- por medio del llamado ideal de lo práctico ${ }^{18}$.

Si cayéramos en ese estructuralismo, podríamos pensar en que aquello que sucedió en la arquitectura en Europa y Estados Unidos durante las tres primeras décadas del siglo $\mathrm{XX}$, vino a reflejarse en América Latina durante los años treinta y cuarenta. Aunque esto puede ser cierto, está claro que las condiciones en la región le entregan un matiz que le da a tal reflejo un tono diferenciado -lo mismo sucede al interior de cada país-. Los jóvenes arquitectos en formación en nuestras academias y en general, los jóvenes estudiantes de las generaciones inmediatamente siguientes - principalmente las de los años sesenta y setenta-, estaban siendo socializados en ambientes de reivindicación cultural que acompañaban las reclamaciones disciplinares particulares: entre las que estaban las que padecía la arquitectura.

Si profundizáramos, seguramente encontraríamos que la generalidad permite pensar en que ciertos proyectos de ampliación educativa en nuestros países, supusieron a su vez la ampliación en la entrada de jóvenes a las universidades. 
Esto es clave para comprender las razones por las cuales una clase media, excluída en diversos formatos del ejercicio racional del poder ${ }^{19}$, aunque con las competencias conceptuales, críticas y técnicas para ejercerlo, se convierte en principal reaccionaria en contra de los señores del poder por todo el contiente suramericano, en muchos casos, convirtiendo al Estado en un enemigo del que era necesario protegerse. A la sensación de exclusión, se suma el ensueño provocado por el triunfo de la Revolución Cubana en 1958 y el surgimiento de imágenes de juventud ${ }^{20}$, la consolidación de una mirada particular en los ejercicios de intervención y asistencia social de la Iglesia Católica en varios de nuestros países y, de su mano, la circulación de los principios de la Teología de la Liberación. Estas cosas - entre tantas otras- alimentaron el espíritu de jóvenes estudiantes latinoamericanos, dentro de los cuales se encontraban los arquitectos.

De tal manera, los ideales de la arquitectura moderna emanzipada de las Bellas Artes y en rompimiento con la historia, eran traducidos - por no decir que eran mezclados en un vívido sincretismo- por quienes -además- se ilusionaron con un nuevo modelo de desarrollo para nuestras respectivas sociedades: no sólo era importante resolver las necesidades de un tentativo usuario de una obra, como pregonó la arquitectura liberada de los yugos del siglo XIX; el arquitecto moderno latinoamericano debía posibilitar la equidad social mediante la resolución sensible de los problemas de los habitantes menos favorecidos en el voráz y excluyente modelo de desarrollo que habían comprado las élites en los centros de poder occidental21.

Sin embargo, quizás como la ironía más encantadora: aquella que reposa en la religiosa utopía, los arquitectos latinoamericanos parecían enamorados de los grandes preceptos del modernismo disciplinar bajo el ya sintetizado 'estilo internacional' y este -enorme paradoja- comenzó a mostrar varias inconsistencias desde los últimos años de la década del cuarenta: momento en que arrivan tales ideas a varios de nuestros países. Los señalamientos que en ese mismo instante se están haciendo dejan ver que el modernismo arquitectónico se convirtió en aquello contra lo cual construyó todo el arsenal conceptual que le dio su origen. Collin Rowe en 19561957 (1978) expone con contundencia las razones por las cuales es posible decir que existe un neo-paladianismo en las obras posteriores a los años treintas en Europa y Estados Unidos: el modernismo llegó al manierismo contra el cual construyó las barricadas en su emancipación.

Por su parte, como si fuera poco, los proyectos urbanos que exigía la rampante modernización en América Latina, convirtieron al modernismo arquitectónico en su basamento principal, conviertiéndolo a su ética y a sus perspectivas:

Hoy en día [1956-1957] la arquitectura moderna está reconocida por los gobiernos y ha recibido el espaldarazo de las grandes corporaciones. Ha aparecido una generación que ya la acepta como algo dado; y, en consecuencia, el arquitecto moderno ya no puede pretender con la seriedad de antes ser el protagonista de una nueva integración de la cultura. Ahora le cuesta mostrarse militante y, al estar menos dispuesto a evangelizar un mundo que, sin haber cambiado excesivamente, sin embargo le ha aceptado, parece más dispuesto a volver a dedicarse a una función específica. (Rowe, 1978, p. 123) 
La paradoja respira con fuerza y se repotencializa en el hecho de que tales proyectos fortalecieron el sector de la construcción, reclutando natualmente al arquitecto moderno en sus filas: ahí una enajenación como la que señala Sérgio Ferro sobre el papel del diseño en el proyecto arquitectónico para el ejercicio disciplinar (Ferro, 1982).

De tal manera por lo menos manierismo y enajenación ${ }^{22}$ parecieron engendrar una crisis al interior de la disciplina que consciente o inconscientemente pudo impulsar la búsqueda de sustitutos en prácticas como el diseño industrial y el diseño gráfico que venían fortaleciéndose dentro del ejercicio mismo del arquitecto moderno.

\section{Diseño y utopía}

Es posible pensar que de aquella crisis se desprendiera una cierta desilusión con la disciplina por parte de algunos críticos, estudiantes y profesionales de la arquitectura, que no tardaron en explorar algunos otros campos de la creación moderna en un cierto intento por hacer del proyecto de desarrollo del país, una realidad económica y socialmente coherente. Los mismos puentes que intentó la crítica arquitectónica con otras áreas del saber, pueden dar cuenta del mismo malestar ${ }^{23}$.

Independientemente de las circunstancias que explican el nacimiento del diseño en cada uno de los países de América Latina, podría ser posible generalizar que cierta parte de su discurso fundacional trazó límites con la arquitectura, basando sus diferencias en torno del problema de la lectura sensible con las dimensiones antropométricas y cognitivas de la población a la que se iba a diseñar un artefacto. Con las artes, señalando la diferencia en el uso de la creatividad y el padecimiento estético, como recreando el discurso que la arquitectura utilizó para su emancipación en el siglo XIX.Y con la ingeniería, principalmente por la idea de que ella no era capaz de comprender las dimensiones 'menos materiales' en la relación hombre-artefacto. En los tres casos, anacronismos que debían ser resueltos.

Es necesario conocer los detalles fundacionales y la memoria sobre las motivaciones de los actores con el fin de ver las formas que adquiría el discurso en consonancia con las ideas. Sin embargo, a partir de algunos de los documentos que dejó el proceso, no es muy complicado percibir que en el esfuerzo organizativo que representaba ALADI había una coincidencia en los actores para comprender un problema regional que podría ser atajado por medio de una disciplina nueva en la región. Una disciplina que por principio cumplía con superar tales anacronismos. Era entonces el asunto de la intervención técnica, económica y cultural de agentes externos en la paranoia que supuso la Guerra Fría y las posibilidades del Diseño Industrial, como heredero del llamado histórico para retenerla. 
Intervención técnica por el hecho de que - por ejemplo- el modelo de sustitución de importaciones, suponía la reproducción nacional acrítica de los procesos de transformación de mercancías en el exterior: se depuraba el proceso pero no se producía aquí el llamado know-how; intervención económica, pues se generaba un lazo de exclusiva direccionalidad con los mercados que promovía aquella reproducción de procesos; e intervención cultural, pues las más diversas relaciones de producción de las mercancías están directamente relacionadas con las necesidades que ellas mismas significan. De tal manera, no sólo era un despropósito replicar los procedimientos para obtener un producto extranjero con nuestra capacidad instalada, sino que era una enajenación considerar que las necesidades por las cuales se diseñaba un producto por fuera del país, respondiera a las expectativas antropométricas y cognitivas de nuestros pueblos. Pero sobre todo -y para hacer apología de Loos- era un delito considerar que el sentido fundamental que exigía el diseño y la producción de esos objetos fuera igual al de la metrópoli, de donde tales modelos provenían. En los tres niveles -reproducción técnica, direccionalidad con los mercados y homogenización cultural- se marcaban evidentes lazos de dependencia y grandes enemigos de nuestra autonomía.

La consideración del problema energético para comunidades de tales características económicas y sociales [rurales y semirurales] (cuyos habitantes aún no figuran en las estadísticas mundiales como consumidores de algunas de las formas modernas de energía, no sólo por no disponer de comodidades que serían indispensables para el más miserable de los pobladores de un país industrializado, sino porque han mantenido una economía de supervivencia y de baja productividad basada en una subexplotación de los recursos naturales renovables) pone de presente grandes contradicciones respecto del tipo de soluciones y alternativas que realmente puede alcanzar una inmensa población marginada del desarrollo. A su vez muestra los tremendos desajustes en la formación y ejercicio profesional del diseñador y su incapacidad actual para contribuir eficazmente a la satisfacción de las inmensas necesidades que aquejan a un elevado porcentaje de población mundial. (Polo, 1980, p.17)

Los argumentos se configuran desde los discursos más elaborados de la ciencia aplicada, como los que se pregonaba en las ideas de Mario Bunge (1984) -que hacían parte de un sentido común muy característico en la época en ciertas esferas de intelectuales-, hasta aquellos sentidos que venían heredándose de la arquitectura moderna según la cual, la técnica era la forma más adecuada de una cultura. En todo caso, como uno de los propósitos más claros que motivaron la creación de ALADI y sobre el que quizás giraba la identidad del grupo - por corroborar en las indagaciones posteriores- como afirma Lernart Svensson en la Sociología de las Profesiones “... las profesiones son actores destacados a la hora de categorizar, clasificar y etiquetar el mundo que nos rodea así como de evaluar casi todo en términos de bueno o malo..." (Svensson, 2003, p.14). El Diseño Industrial se mostraba como una disciplina sintetizadora del cambio y un posibilitador de la autonomía al estar estrechamente ligada con el pensamiento tecnológico desde donde se procuraba el desarrollo económico, social y cultural de la región. 
Nuestro acontecer muestra otro ángulo del'desarrollo humano' [...] Me refiero a la oposición ya establecida entre los poseedores de los recursos naturales (base material) y los poseedores del conocimiento operacional (tecnología) [...] En la lucha por el control de la sobrevivencia, los poseedores del conocimiento operacional se apropian de los recursos naturales de la periferia, con lo cual, abortan la posibilidad de (a partir de nuestros recursos y trabajo, desarrollar nuestra propia tecnología), por un lado; por otro, seguir imponiendo la dependencia periférica a los modelos de sobrevivencia metropólica a escala de economía planetaria; explotadores y explotados, superculturas y subculturas. Cabe aquí hacer la pregunta ¿el desarrollo para quién? Como opción de sobrevivencia, como concreción vital más allá de distracciones ideológicas y/o políticas, la generación de una tecnología propia, es nuestra única opción de desarrollo humano. (Gámez, 1980, p. 5)
Podemos decir entonces que la consolidación de ALADI es un esfuerzo organizativo de gran magnitud en la que se hace visible una crítica interna sobre el proceso de modernización de los países de la región. En el discurso constitutivo que reposa en actas y algunos artículos ${ }^{24}$, es relativamente claro el interés de los fundadores por detener la intromisión de agentes externos en los procesos de modernización de los países de la región, dado el lazo de dependencia que genera el círculo tecnología-economía-cultura.

Tales relaciones pueden tener génesis en las lecturas que se hacían en América Latina sobre los distintos cambios sociales que viven sus países durante el siglo XX -en especial, luego de los años treinta-, las promesas y las desilusiones que suponen los preceptos generales de la arquitectura moderna - de donde provienen varios de los fundadores- y la idea de que el conocimiento -y por consecuencia la creatividad- debía ser aplicado para resolver las necesidades sentidas de las poblaciones, como el ensueño de la gran promesa del gran proyecto moderno. 
Más allá de si hubo o no modernidad en la región - discusión que por el momento supera nuestro propósito- varias de las ideas expuestas en este escrito parecen haber configurado una cierta cantidad de imágenes sobre ella en los fundadores de la asociación. Imágenes que con el paso del tiempo se fortalecieron en la magnitud de un proyecto asociativo de las proporciones que sugiere ALADI para la época en que se dio.

\section{Notas}

${ }^{1}$ Este trabajo pretende estar hecho desde la mirada de la historia social y es una derivación del proyecto "Aspectos sociales que permitieron que el Diseño Industrial se profesionalizara académicamente en Colombia”. Así mismo es parte de una tesis doctoral que está en proceso llamada: "ALADI: da criatividade social à libertação de nossos povos".

${ }^{2}$ Diseñador Industrial de la UJTL de Bogotá, Magíster en Sociología de la Universidad del Valle, es estudiante del doctorado en Arquitetura e Design en la Universidade de São Paulo. Es profesor del Departamento de Diseño de la Universidad del Valle en Cali, director de Nobus, Grupo de Investigación en Diseño y miembro del Comité Editorial de la Revista Nexus. Ha sido ponente en eventos en Colombia, Argentina y Brasil. Es el autor del libro "Creatividad Social. La Profesionalización del Diseño Industrial en Colombia". Compilador de la serie "Improntas de un error" y con Augusto Solórzano coeditor de "Diseño Dialoga”.

${ }^{3}$ Diseñador Industrial de la Universidad Federal de Río de Janeiro y Doctor en Historia Social por la Universidad Federal Fluminense. Es profesor en la Facultad de Arquitetura e Urbanismo de la Universidad de São Paulo. Es miembro del consejo editorial de las revistas Estudios en Diseño y miembro del Consejo Editorial de la Revista de Arcos/ESDI. Es autor de lo libro “ABDI e APDINS RJ: História das Associações Pioneiras de Design do Brasil”. Es uno de los coordinadores de la colección de los libros "Pensando o Design” y organizó el libro "O Papel Social do Design Gráfico".

${ }^{4}$ Representantes de estos cinco países se encuentran siempre en los diferentes momentos como signatarios de los compromisos que se iban adquiriendo en los escenarios que precedieron la constitución oficial de ALADI en noviembre de 1980 en Colombia. Desde Interdesign 1978, reunión de Bombay 1979, XI ICSID en Ciudad de México 1979 y reunión en Medellín en 1980.

${ }^{5}$ Sus percepciones sobre el hecho resultan corroborables por Arthur Pulos (1988) y, por analogía, en la explicación del caso turco, tan lúcidamente construido por Alpay Er, Fatma Korkut y Özlem Er.

${ }^{6} \mathrm{O}$, lo que puede resultar ser igual, con una mirada crítica hacia tales postulados, pues parecían desgastarse en la práctica de la arquitectura y su relación con el momento histórico.

${ }^{7}$ El primer Comité Ejecutivo de ALADI nombrado en ese primer Congreso fue el siguiente: Presidente: Rómulo Polo, Colombia;Vicepresidente: Iván Espín, Cuba;Vicepresidente:Valeria London, Brasil; Secretario: Luis Fernando Zapata, Colombia; Tesorero: Jesús Gámez, Colombia (ALADI, 1980: 9).

${ }^{8}$ Por poner un ejemplo, es interesante el caso del conocido Star System norteamericano y las maneras como circularon modelos de belleza femenina, roles sociales y expectativas en general por la región. Los cuidadosos textos de Pedro Duque et al. (Duque, Silva, Bernal, \& Conde, 2012), así como los recientes trabajos de Claudia Reyes (Reyes, 2013) dan cuenta del hecho.

${ }^{9}$ Reservas manifestadas en un sinnúmero de formatos. Uno de ellos, el llamado Cine Político Marginal; corriente 'alterna' en la producción audiovisual de la región, en la cual se pretendió exponer el proceso de modernización al contrario de la manera como era presentado por "el establecimiento", es decir, como un proceso incompleto, violento, desigual y, en todo caso, imperialista. La tesis de Gloria Pineda da luces importantes sobre el hecho (Pineda, 2013). Sugerimos revisar igualmente (Pineda \& Buitrago, 2012).

${ }^{10}$ Y a manera de sospecha y arriesgada conjetura, en la conformación de escuelas como la HfG de Ulm, dada su implementación con el tentativo dinero del plan Marshall y la evidente influencia que supone el tránsito de entre otros, de los esposos Eames. 
${ }^{11}$ Varios indicios sugieren que esto sucedió en Colombia durante los años sesenta, de donde se desprende la fundación de Artesanías de Colombia y la redacción de varios programas de estudio en universidades del país. Por su parte Alpay Er et al. exponen con precisión algunos de los detalles involucrados de este proceso en Turquía (2003). De igual manera, Arthur Pulos deja ver el interés del gobierno norteamericano con el asunto (1988).

${ }^{12}$ No tardaría en manifestarse en la música con la avalancha y traducción del rock and roll británico, con sus respectivos consumos, prejuicios y reproducciones.

${ }^{13}$ La comparación de Beatriz Colomina et al. (2013) en la exposición Latin American, muestra con claridad las maneras como el estilo internacional se propagó por la región sin mayores distinciones.

${ }^{14}$ Como reproduciendo el axioma weberiano según el cual las acciones racionales se relacionan con los fines y valores que las respalda (2008).

${ }^{15}$ Las nociones de jurisdicción y discrecionalidad son trabajadas por Eliot Freidson (2001) y Andrew Abbott (1988) y, tal como las hemos comprendido, complementan -incluso potencian- las miradas al problema de la profesionalización cuando se observa bajo los lentes bourdieanos del campo.

16 “...de modo que, presentándose como intérprete de ese inconsciente colectivo, el arquitecto moderno ha añadido otro papel a su repertorio de Sigfrido-San Jorge. Ahora se ha convertido en la persona que debe intuir lo que debe ser, en el mediador entre la vida psicológica inconsciente del 'pueblo' y los medios tecnológicos a su disposición, en arúspice, profeta y gurú. Se ha convertido no sólo en protagonista de la renovación social sino también, podríamos decir, en partera de la historia - de la forma históricamente significativa...” (Rowe, 1978, p. 125).

${ }^{17}$ Las influencias se expresan tanto en latinoamericanos estudiando y trabajando con los ideólogos del movimiento moderno en el exterior, como en la visita y el trabajo de varios de estos personajes en países de América Latina.

${ }^{18}$ Para hacer apología de Frank Safford (1989).

${ }^{19}$ Por la perpetuación de la élite en el poder bien bajo ejercicios hegemónicos de cuadros políticos como sucedió en México con el PRI, o la repartición de los cuadros y el fortalecimiento del bipartidismo en Colombia en el llamado Frente Nacional, o las dictaduras en el cono sur.

${ }^{20}$ Podría generalizarse la idea de Jaime Jaramillo en sus memorias “...en América Latina, especialmente en los medios juveniles y estudiantiles [...] se expandió el culto a dos figuras dirigentes, Fidel Castro [y] -el Ché Guevara-. Los estudiantes de mi generación que militábamos en la izquierda [en Colombia] teníamos en nuestros cuartos un retrato de Lenin. Los de la década del sesenta tenían uno o varios de la romántica figura del Che Guevara...”(Jaramillo, 2007, p.167).

${ }^{21}$ Para ese momento, para muchos intelectuales latinoamericanos estaba claro que el Estado era un enemigo del que era necesario cuidarse, pues, entre otras cosas, representaba el ingreso de países externos en la autonomía nacional. Las anécdotas son numerosas: desde las visitas y diagnósticos de Rudolf Atcon a las diferentes universidades de la región, hasta el tránsito de dinero, personalidades y edificios en los diferentes proyectos universitarios y nacionales, contratados y/o mediados por los gobiernos de turno: por ejemplo con la Fundación Rockefeller.

${ }^{22}$ Por definición grandes enemigos del basamento conceptual de la arquitectura moderna -habría que citar nuevamente a Loos- y absolutos enemigos de la equidad social para la lectura de algunos actores en Latinoamérica.

${ }^{23}$ Las lecturas con la crítica histórica, sociológica, semiótica, estética, psicoanalítica, etc., abundan en la literatura de críticos como Colin Rowe, Manfredo Tafuri, Kenneth Frampton, Sérgio Ferro entre otros.

${ }^{24}$ Aún hace falta el diálogo cercano con los actores, que seguro entregarán matices a cada una de estas ideas, que son, como hemos indicado, un principio que pretende el ordenamiento de hipótesis. 


\section{Referencias}

Abbott, A. (1988). The System of Professions. London: The University of Chicago Press.

Acero, J. (1980). Retorno al Oficio. La Carreta del Diseño, (3), p. 12.

ALADI (1980). Acta de constitución de la Asociación Latinoamericana de Diseño Industrial, ALADI. Bogotá: Inédito.

Alpay Er, H., Korkut, F. \& Er, Ö. (2003). U.S. Involvement in the Development of Design in the Periphery: The Case History of Industrial Design Education in Turkey, 1950s-1970s. Design Issues, 19 (2), pp. 17-34.

Arias, C. (2007). Umbrales Estéticos: Entre el Pensamiento y el Disfrute. Medellín: La Carreta Editores.

Braga, M. (10-12 de Octubre de 2009). O Design brasileiro nas indústrias de eletrodomésticos dos anos 1960: o caso da Walita. Recuperado el 1 de Septiembre de 2010, de V Congresso Internacional de Pesquita em Design. BAURU- SP- BRASIL 2009: Tomado de http:// www.faac.unesp.br/ciped2009/anais/Hist\%f3ria\%20do\%20Design/

Bloch, M. (2002). Apologia da história. Ou o ofício de historiador. Rio de Janeiro: Zahar.

Bunge, M. (1984). Ciencia Básica, Ciencia Aplicada, Técnica y Producción: Diferencias y Relaciones (Conferencia dictada en el Instituto Tecnológico de Santo Domingo, el 22 de Mayo de 1984), Ciencia y Sociedad, pp. 167-182.

Colomina, B., Fowler, J., Kotsioris, E., Mullane, M., Panteleyeva, M., Pozzi, C., Risteen, N. (2013). Latin American. São Paulo: Exposición.

Devalle, V.(2009). La Travesía de la Forma. Emergencia y Consolidación del Diseño Gráfico (1948-1984). Buenos Aires: Paidós.

Duque, P., Silva, L., Bernal, A. \& Conde, J. (2012). Los Heraldos: Miradas locales de la gráfica globalizada. Bogotá: Fundación Universidad de Bogotá Jorge Tadeo Lozano.

Ferro, S. (1982). O canteiro e o desenho. São Paulo: Projeto.

Freidson, E. (2001). Professionalism. The Third Logic. Great Britain: The University of Chicago Press.

Gámez, J. (1980). Del Método y la Sociedad. La Carreta del Diseño, (3), pp. 4-5.

Giddens, A., \& Gil, A. J. L. (1997). Modernidad e identidad del yo: El yo y la sociedad en la época contemporánea. Barcelona: Península.

Jaramillo, J. (2007). Jaime Jaramillo Uribe. Memorias Intelectuales. Bogotá:Taurus.

Pamio, O. (1981). Hacia un Diseño Independiente. Revista Módulo, (2), pp. 1-2.

Pineda, G. \& Buitrago, J. (2013). Análisis de las Formas de Representación de las Ideas de Nación en el Cine Político Marginal Colombiano (1966-1976). Cali: Inédito.

Pineda, G. \& Buitrago, J. (2012). Convergencias y Configuraciones. Una aproximación histórica a la concreción de una ideología en el cine político marginal de los años 60's y 70's en Colombia. Nexus, (11), pp. 110-131.

Polo, R. (1980). Interdiseño 78, Valle de Bravo, México. Documento de Intención [Hacia la consolidación de ALADI]. La Carreta del Diseño, (3), pp. 17-18.

Pulos, A. J. (1988). The American design adventure, 1940-1975. Cambridge, Mass: MIT Press.

Reyes, C. (2013). Imagen, mujer y cultura: desterritorialización y apropiación de imágenes del star system. Nexus, (13), pp. 68-85.

Rowe, C. (1978). Manierismo y arquitectura moderna y otros ensayos. Barcelona: Gustavo Gili.

Safford, F. (1989). El Ideal de lo Práctico. Bogotá: El Áncora.

Svensson, L. (2003), Introducción, en: M. Sánchez, J. Sáez, \& e. Al., Sociología de las Profesiones: Pasado, Presente y Futuro. Murcia: Diego Marín.

Uribe, B., Abramovitz, J., Polo, R. (1980). Propuesta para la formación de ALADI. Bombay, India. Enero de 1979. La Carreta del Diseño, (3), p. 18.

Weber, M. (2008). Economía y sociedad. Esbozo de sociología comprensiva. México: Fondo de Cultura Económica.

Recibido: Abril 15 / Aprobado: mayo 28 de 2014 